\title{
Impact of Primary Site Surgery on Survival of Patients with de novo Stage IV Breast Cancer
}

This article was published in the following Dove Press journal:

Cancer Management and Research

\section{Zhen Huang* \\ Qixing Tan (D) \\ Qinghong Qin \\ Qinguo Mo \\ Changyuan Wei}

Department of Breast Surgery, Guangxi Medical University Cancer Hospital, Nanning, People's Republic of China

*These authors contributed equally to this work
Correspondence: Qinguo Mo;

Changyuan Wei

Department of Breast Surgery, Guangx

Medical University Cancer Hospital, 7I

Hedi Road, Nanning 53002I, People's

Republic of China

$\mathrm{Tel}+86-77 \mathrm{I}-5308593 ;+86-77 \mathrm{I}-5308593$

Fax +86-77I-53I2000

Email qgmol35@263.net;

weichangyuan@gxmu.edu.cn
Purpose: The efficacy of primary site surgery in patients with de novo stage IV breast cancer remains controversial. However, few real-world studies have evaluated the benefits of local surgery on the primary site of stage IV breast cancer in China. The purpose of this study was to investigate the role of local surgery in the de novo stage IV breast cancer.

Materials and Methods: Women with metastatic breast cancer at diagnosis were identified from Guangxi medical university cancer hospital (China) database from 2009 to 2017. The clinical and tumor features, surgical treatment, and survival rates were compared between surgical and non-surgical patients.

Results: Two hundred forty-three patients were included, of whom 125 underwent primary site surgery. Patients who underwent surgery were more often had small primary tumors, fewer lymph node metastases, and had less visceral involvement. Patients in the surgery group had dramatically longer OS (median 35 vs 22 months, log-rank $P=0.006$ ). Stratified survival analysis showed that patients with bone metastasis alone or $\leq 3$ metastasis benefit from surgery, while patients with visceral metastasis did not benefit from surgery. In multivariate analysis, surgical treatment, estrogen receptor status, progesterone receptor status and visceral metastases remained independent factors for survival.

Conclusion: Surgical resection of the primary site can improve survival in selected de novo stage IV breast cancer patients.

Keywords: stage IV breast cancer, surgery, survival

\section{Introduction}

Breast Cancer is the most common cancer among women globally and in China and is the second leading cause of cancer death. It is estimated that $5-10 \%$ of women with breast cancer will be diagnosed with stage IV breast cancer at the time of their initial diagnosis. ${ }^{1}$ Stage IV breast cancer is still incurable and the standard treatment for these patients is systemic therapy, including chemotherapy, endocrine therapy, radiation therapy and/or targeted therapy. ${ }^{2}$

The efficacy of surgical resection of the primary site of Stage IV breast cancer remains controversial and several recent studies have reported conflicting results. ${ }^{3,4}$ Surgery for primary tumors of Stage IV breast cancer is usually performed on patients who have completed systemic therapy and have "impending complications such as skin ulcers, bleeding, and pain." And the conventional wisdom is that this kind of surgery does not offer survival benefits. ${ }^{5,6}$ However, recent retrospective clinical studies have shown a positive impact on local control and overall survival in newly diagnosed stage IV breast cancer patients after primary site tumor resection. $^{7-9}$ Conversely, some studies have shown that surgery for metastatic 
breast cancer does not translate into survival benefits. ${ }^{10,11}$ However, these retrospective studies were influenced by the selection bias, because they mainly included younger patients or with single metastatic lesion, only the bone or soft tissue metastasis. Randomized clinical trials are now under way but have been slow to accrue and report, and the results are still contradictory. A randomized prospective trial from India (NCT00193778) ${ }^{12}$ and a registrybased prospective study from the United States $\left(\right.$ TBCRC013) ${ }^{4}$ have shown that patients with stage IV breast cancer who underwent surgery had no survival advantage over patients with stage IV breast cancer who received chemotherapy alone. In contrast, a well-designed Turkish prospective randomized trial (MF07-01) ${ }^{3}$ showed that topical regional therapy was beneficial for overall survival in younger patients ( $<55$ years), those with "only bone metastases" and those with positive ER status. In that study, patients with liver and lung metastases had worse outcomes. However, it is worth noting that the primary end-point of 3-year OS benefit was not met, but the OS differences were observed during long-term follow-up (5-year).

Because of the clinical and biological heterogeneity of breast cancer, it is not clear which patients are expected to benefit from local surgery. The prognosis of stage IV breast cancer varies depending on the site of metastasis, which may provide a basis for determining which patients may benefit from local surgery. The aim of our current study is to determine whether local surgery improves overall survival in patients with de novo metastatic breast cancer and to identify characteristics of those who would benefit from surgery.

\section{Materials and Methods Study Population}

In total, 243 patients who were initially diagnosed with stage IV primary invasive breast cancer at Guangxi Medical University Cancer Hospital between 2009 and 2017 were included in the study. Patients were included in the study if they met the following inclusion criteria: 1) had a pathological diagnosis of breast cancer; 2) had metastasis at the time of diagnosis of breast cancer; 3 ) life expectancy of more than 6 months. Patients with incomplete follow-up data and a previous history of cancer or malignancy were excluded. Ethical approval for the study was obtained from the Ethics Committee of Guangxi Medical University Cancer Hospital. It was designed as a retrospective study and the results would not affect the clinical care of the patients. Therefore, patient approval and informed consent were waived off by the institutional review boards. We confirmed that the patient data was anonymized and confidential.

\section{Data Collected}

Patients' data were obtained by a review of their medical history. The demographic information and tumor characteristics were collected, which included age at diagnosis, residence, menopause status, pathologic type, tumor stage, grade, molecular subtype, estrogen and progesterone receptor status, human epidermal growth factor receptor2 (HER-2) status, classification and number of metastatic sites. Patients' treatments including surgery, chemotherapy, endocrine therapy, targeted therapy and radiation therapy were also recorded. The OS is calculated from the time of diagnosis until the last follow-up or time of death from any cause.

\section{Statistical Methods}

SPSS 22.0 software (SPSS Inc., Chicago, IL) was used for statistical analyses. Patients' clinical and tumor characteristics were analyzed using descriptive statistics, including frequency, ratio, median, mean, and standard deviation. The categorical variables were compared by chi-square test or Fisher's exact test, and the continuous variables were compared by Mann-Whitney test. Kaplan-Meier analysis was utilized to generate survival curve, along with Log rank test for statistical significance. Additionally, independent prognostic factors were identified by Cox multivariate proportional hazards regression model. A two-sided $P<0.05$ indicated statistical significance.

\section{Ethical Approval}

Our study complied with the 1964 Helsinki Declaration and its later amendments or comparable ethical standards.

\section{Results}

\section{Population Characteristics}

Table 1 summarizes the characteristics of 243 patients with stage IV breast cancer included in this study. The mean age at diagnosis was 50.0 years (range $20-83$ years). More than half of the patients $(125,51.4 \%)$ eventually underwent surgical removal of the primary lesion, and most underwent modified radical mastectomy (112, 89.6\%), 
Table I Characteristics of the Study Population

\begin{tabular}{|c|c|c|}
\hline Variable & $\begin{array}{l}\text { No. Patients } \\
(\mathrm{N}=243)\end{array}$ & $\begin{array}{l}\text { Percentage } \\
\text { (\%) }\end{array}$ \\
\hline Age at diagnosis (years) & & \\
\hline$<50$ & 122 & 50.2 \\
\hline$\geq 50$ & 121 & 49.8 \\
\hline Mean & 50.04 & - \\
\hline Range & $20-83$ & - \\
\hline Histology & & \\
\hline IDC & 218 & 89.7 \\
\hline LC & 8 & 3.3 \\
\hline Other & 17 & 7.0 \\
\hline T stage & & \\
\hline $\mathrm{TI}$ & 5 & 2.1 \\
\hline $\mathrm{T} 2$ & 71 & 29.2 \\
\hline T3 & 31 & 12.7 \\
\hline $\mathrm{T} 4$ & 136 & 56.0 \\
\hline $\mathrm{N}$ stage & & \\
\hline No & 14 & 5.8 \\
\hline $\mathrm{NI}$ & 70 & 28.8 \\
\hline N2 & 77 & 31.7 \\
\hline N3 & 82 & 33.7 \\
\hline Metastatic site & & \\
\hline Bone & 134 & 55.1 \\
\hline Lung & 99 & 40.7 \\
\hline Liver & 72 & 29.6 \\
\hline Brain & 15 & 6.2 \\
\hline Soft tissue & 83 & 34.2 \\
\hline Visceral organ & 147 & 60.5 \\
\hline Number of metastatic sites & & \\
\hline$<3$ & 130 & 53.5 \\
\hline$\geq 3$ & 113 & 46.5 \\
\hline ER status & & \\
\hline Positive & 162 & 66.7 \\
\hline Negative & 81 & 33.3 \\
\hline PR status & & \\
\hline Positive & 141 & 58.0 \\
\hline Negative & 102 & 42.0 \\
\hline HER2 status & & \\
\hline Positive & 118 & 48.6 \\
\hline Negative & 113 & 46.5 \\
\hline Unknown & 12 & 4.9 \\
\hline Surgery & & \\
\hline Yes & 125 & 51.4 \\
\hline No & 118 & 48.6 \\
\hline Chemotherapy & & \\
\hline Yes & 213 & 87.7 \\
\hline No & 30 & 12.3 \\
\hline Hormone therapy & & \\
\hline Yes & 87 & 35.8 \\
\hline No & 156 & 64.2 \\
\hline
\end{tabular}

(Continued)
Table I (Continued).

\begin{tabular}{|l|l|l|}
\hline Variable & $\begin{array}{l}\text { No. Patients } \\
(\mathbf{N}=\mathbf{2 4 3})\end{array}$ & $\begin{array}{l}\text { Percentage } \\
\text { (\%) }\end{array}$ \\
\hline $\begin{array}{l}\text { Anti-HER2 therapy } \\
\text { Yes }\end{array}$ & 47 & \\
No & 196 & 19.3 \\
\hline Radiotherapy & & 80.7 \\
Yes & 48 & \\
No & 195 & 19.8 \\
\hline
\end{tabular}

Abbreviations: IDC, infiltrative ductal carcinoma; LC, lobular-carcinoma; $E R$, estrogen receptor; HER2, human epidermal-growth factor 2; PR, progesterone receptor.

and the remaining had simple mastectomy or lumpectomy (10.4\%). The median follow-up time was 42 months and the median survival time was 29 months. With regard to tumor characteristics, the primary tumors were mainly $\mathrm{T} 4$ (affect the skin) at presentation (56.0\%), infiltrating ductal carcinoma (89.7\%), ER-positive (66.7\%) and PR-positive $(58.0 \%)$. The most common distant metastases were bone metastases $(55.1 \%)$, followed by lung metastases (40.7\%) and liver metastases $(29.6 \%)$. Overall, more than half of the patients had visceral metastases $(60.5 \%)$. For overall population, $72(29.6 \%)$ patients had only bone metastasis, $44(18.1 \%)$ only lung metastasis, $16(6.6 \%)$ only liver metastasis, $30(12.3 \%)$ only soft tissue metastasis and one patient $(0.4 \%)$ had only cerebral metastasis. There were 162 patients were hormone receptor positive, and 87 (53.7\%) patients received endocrine therapy. Besides, 118 patients were HER2 positive, but only 47 (39.8\%) patients received HER2-targeted therapy.

Table 2 shows the comparison of clinical and neoplastic characteristics between the surgical and non-surgical groups. As expected, patients who did not undergo surgery were more likely to have visceral metastases and multiple metastatic diseases. Regarding tumor staging, patients without surgery are more likely to be T4. A significantly higher proportion of patients in the surgery group have lower T stage (T1-T3) $(\mathrm{p}=$ $0.009)$, lower $\mathrm{N}$ stage $(\mathrm{N} 1-\mathrm{N} 3)(P=0.027)$, and received endocrine therapy $(P=0.000)$. There were no significant differences in patient and tumor characteristics such as age distribution; menstrual status; HER2 status; and HR status; receipt of chemotherapy or radiotherapy; receipt of anti-HER2 therapy; and prevalence of bone, liver, or brain metastasis.

\section{Univariable and Multivariable Analysis}

Univariable analysis using Cox hazard model showed that the mortality risk in the surgical group was significantly 
Table 2 Comparison of Clinical and Tumor Characteristic Between Surgery Group and No Surgery Group

\begin{tabular}{|c|c|c|c|}
\hline Variable & $\begin{array}{l}\text { Patients with } \\
\text { Surgery }(\mathrm{N}=125)\end{array}$ & $\begin{array}{l}\text { Patients without } \\
\text { Surgery }(\mathrm{N}=118)\end{array}$ & $P$ \\
\hline $\begin{array}{l}\text { Age at diagnosis } \\
\text { (years) } \\
<50 \\
\geq 50\end{array}$ & $\begin{array}{l}64(51.2 \%) \\
61(48.8 \%)\end{array}$ & $\begin{array}{l}58(49.2 \%) \\
60(50.8 \%)\end{array}$ & 0.854 \\
\hline $\begin{array}{l}\text { T stage } \\
\text { TI } \\
\text { T2 } \\
\text { T3 } \\
\text { T4 }\end{array}$ & $\begin{array}{l}4(3.2 \%) \\
46(36.8 \%) \\
17(13.6 \%) \\
58(46.4 \%)\end{array}$ & $\begin{array}{l}I(0.8 \%) \\
24(20.3 \%) \\
14(11.9 \%) \\
79(67.0 \%)\end{array}$ & 0.009 \\
\hline $\begin{array}{l}\text { N stage } \\
\text { N0 } \\
\text { N1 } \\
\text { N2 } \\
\text { N3 }\end{array}$ & $\begin{array}{l}12(9.6 \%) \\
35(28.0 \%) \\
41(32.8 \%) \\
37(29.6 \%)\end{array}$ & $\begin{array}{l}2(1.7 \%) \\
35(28.0 \%) \\
36(30.5 \%) \\
45(38.1 \%)\end{array}$ & 0.027 \\
\hline $\begin{array}{l}\text { Metastatic site } \\
\text { Bone } \\
\text { Lung } \\
\text { Liver } \\
\text { Brain } \\
\text { Soft tissue } \\
\text { Visceral organ }\end{array}$ & $\begin{array}{l}69(55.2 \%) \\
39(31.2 \%) \\
34(27.2 \%) \\
5(4.0 \%) \\
31(24.8 \%) \\
64(51.2 \%)\end{array}$ & $\begin{array}{l}66(55.9 \%) \\
60(50.8 \%) \\
38(32.2 \%) \\
10(8.5 \%) \\
52(44.1 \%) \\
84(71.2 \%)\end{array}$ & $\begin{array}{l}0.909 \\
0.002 \\
0.395 \\
0.158 \\
0.001 \\
0.001\end{array}$ \\
\hline $\begin{array}{l}\text { Number of } \\
\text { metastatic sites } \\
<3 \\
\geq 3\end{array}$ & $\begin{array}{l}116(92.8 \%) \\
9(7.2 \%)\end{array}$ & $\begin{array}{l}93(78.8 \%) \\
25(21.2 \%)\end{array}$ & 0.327 \\
\hline $\begin{array}{l}\text { ER status } \\
\text { Positive } \\
\text { Negative }\end{array}$ & $\begin{array}{l}87(69.6 \%) \\
38(30.4 \%)\end{array}$ & $\begin{array}{l}75(63.6 \%) \\
43(36.4 \%)\end{array}$ & 0.320 \\
\hline $\begin{array}{l}\text { PR status } \\
\text { Positive } \\
\text { Negative }\end{array}$ & $\begin{array}{l}74(59.2 \%) \\
51(40.8 \%)\end{array}$ & $\begin{array}{l}67(56.8 \%) \\
51(43.2 \%)\end{array}$ & 0.704 \\
\hline $\begin{array}{l}\text { HER2 status } \\
\text { Positive } \\
\text { Negative } \\
\text { Unknown }\end{array}$ & $\begin{array}{l}64(51.2 \%) \\
58(46.4 \%) \\
3(2.4 \%)\end{array}$ & $\begin{array}{l}53(44.9 \%) \\
55(46.6 \%) \\
10(8.5 \%)\end{array}$ & 0.081 \\
\hline $\begin{array}{l}\text { Chemotherapy } \\
\text { Yes } \\
\text { No }\end{array}$ & $\begin{array}{l}119(95.2 \%) \\
6(4.8 \%)\end{array}$ & $\begin{array}{l}94(79.7 \%) \\
24(20.3 \%)\end{array}$ & 0.136 \\
\hline $\begin{array}{l}\text { Endocrine therapy } \\
\text { Yes } \\
\text { No }\end{array}$ & $\begin{array}{l}58(46.4 \%) \\
67(53.6 \%)\end{array}$ & $\begin{array}{l}29(24.6 \%) \\
89(75.4 \%)\end{array}$ & 0.000 \\
\hline $\begin{array}{l}\text { Anti-HER2 therapy } \\
\text { Yes } \\
\text { No }\end{array}$ & $\begin{array}{l}25(20.0 \%) \\
100(80.0 \%)\end{array}$ & $\begin{array}{l}21(17.8 \%) \\
97(82.2 \%)\end{array}$ & 0.062 \\
\hline
\end{tabular}

(Continued)
Table 2 (Continued).

\begin{tabular}{|l|l|l|l|}
\hline Variable & $\begin{array}{l}\text { Patients with } \\
\text { Surgery (N = 125) }\end{array}$ & $\begin{array}{l}\text { Patients without } \\
\text { Surgery (N = 1 1 8) }\end{array}$ & $P$ \\
\hline $\begin{array}{l}\text { Radiotherapy } \\
\text { Yes }\end{array}$ & $34(27.2 \%)$ & $14(11.9 \%)$ & 0.052 \\
No & $91(72.8 \%)$ & $104(88.1 \%)$ & \\
\hline
\end{tabular}

Abbreviations: IDC, infiltrative ductal carcinoma; LC, lobular carcinoma; ER, estrogen receptor; HER2, human epidermal growth factor 2; PR, progesterone receptor.

lower than that in the nonsurgical group $(\mathrm{HR}=0.53 ; 95 \%$ CI, 0.36-0.86; $P=0.002$, Table 3). In addition, we observed that visceral organ metastasis $(P=0.000)$, ER status $(P=0.001)$ and PR status $(P=0.029)$ were the prognostic factors in patients with de novo stage IV breast cancer, as shown in Table 3. Multivariable analysis showed that surgery $(P=0.000)$, Visceral organ metastasis $(P=0.000)$, ER status $(P=0.000)$, and PR status $(P=$ $0.002)$, were independent prognostic factors in de novo stage IV breast cancer, as shown in Table 4.

\section{Effect of Surgery on Overall Survival}

The median OS was 29 months for the entire study population. The overall survival of the surgical patients was significantly higher than that of the non-surgical patients (median survival: 35 months vs 22 months; $P=0.006$ ). The Kaplan-Meier survival curve is shown in Figure 1.

\section{Subgroup Analysis of Overall Survival}

Subgroup analysis indicates that for patients with only bone metastases or numbers of metastases $\leq 3$, local resection of the primary tumor significantly prolonged overall survival (median survival: 40 months vs 23 months, $P=$ 0.017; median survival: 35 months vs 22 months; $P=$ 0.014; Figures 2 and 3). Surgery was not associated with better survival in patients with visceral metastases (median survival: 26 months vs 23 months, $P=0.685$; Figure 4 ).

\section{Discussion}

At present, the incidence of breast cancer has ranked first in the world female malignant tumor, is one of the main causes of death of female cancer patients. In new-onset breast cancer, $3.5 \%$ to $10 \%$ of patients have distant metastasis at the time of initial diagnosis. At present, chemotherapy and endocrine therapy are the primary treatment for 
Table 3 Univariable Analysis Predicting OS in Stage IV Breast Cancer Patients

\begin{tabular}{|l|l|l|l|}
\hline Variable & N & HR (95\% Cl) & P value \\
\hline Surgery (yes vs no) & 243 & $0.53(0.36-0.86)$ & 0.002 \\
Age $(<50$ vs $\geq 50$ yr) & 243 & $1.12(0.75-1.27)$ & 0.709 \\
Bone metastasis & 243 & $0.84(0.63-1.63)$ & 0.746 \\
Visceral organ metastasis & 243 & $2.15(1.22-3.86)$ & 0.000 \\
Number of metastases(continuous) & 243 & $1.24(0.69-1.54)$ & 0.054 \\
ER(+ vs.-) & 243 & $0.66(0.59-0.94)$ & 0.001 \\
PR(+ vs.-) & 243 & $0.73(0.58-0.82)$ & 0.029 \\
HER2(+ vs.-) & 243 & $1.46(0.62-1.83)$ & 0.065 \\
\hline
\end{tabular}

Abbreviations: HR, hazard ratio; ER, estrogen receptor; PR, progesterone receptor; HER2, human epidermal growth factor 2.

Table 4 Multivariable Analysis Predicting OS in Stage IV Breast Cancer Patients

\begin{tabular}{|l|l|l|l|}
\hline Variable & N & HR (95\% Cl) & P value \\
\hline Surgery (yes vs no) & 243 & $0.56(0.32-0.78)$ & 0.000 \\
Age $(<50$ vs $\geq 50$ yr) & 243 & $1.01(0.73-1.33)$ & 0.812 \\
Bone metastasis & 243 & $0.79(0.54-1.26)$ & 0.062 \\
Visceral organ metastasis & 243 & $2.38(1.37-3.35)$ & 0.000 \\
Number of metastases(continuous) & 243 & $1.05(0.72-1.48)$ & 0.069 \\
ER(+ vs.-) & 243 & $0.54(0.41-0.85)$ & 0.000 \\
PR(+ vs.-) & 243 & $0.68(0.55-0.82)$ & 0.002 \\
HER2(+ vs.-) & 243 & $1.52(0.81-1.66)$ & 0.553 \\
\hline
\end{tabular}

Abbreviations: HR, hazard ratio; ER, estrogen receptor; PR, progesterone receptor; HER2, human epidermal growth factor 2.

advanced breast cancer, and the role of resection of primary focus in the treatment of Stage IV breast cancer is still controversial.

Some studies suggest that resecting the primary tumor can increase the release of angiogenic factors, increase the

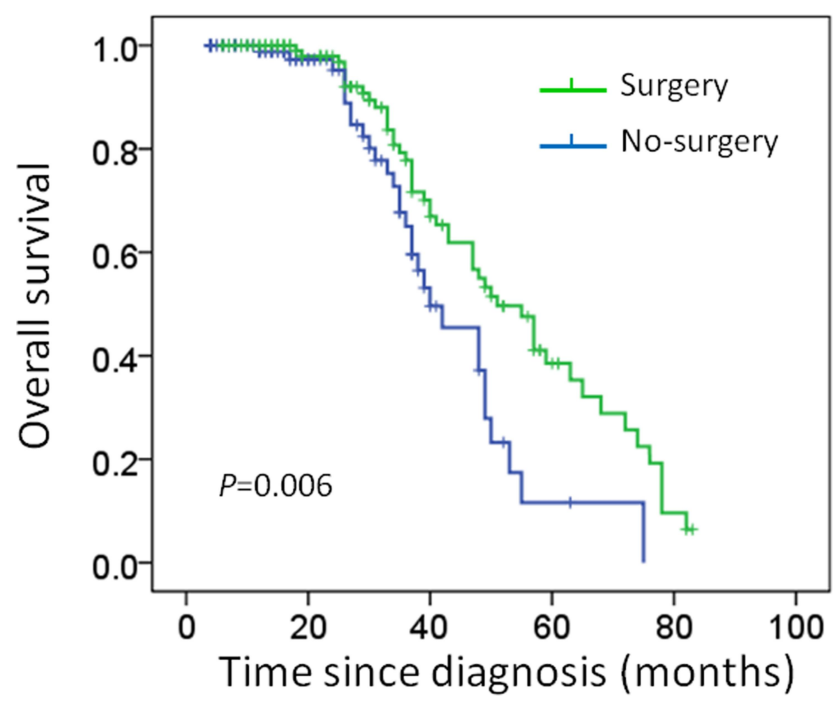

Figure I Kaplan-Meier curves estimate overall survival in de novo stage IV breast cancer (Median survival was 35 months in the surgery group vs 22 months in the no surgery group; Log rank test: $P=0.006$ ). angiogenesis of metastatic tumor and the infiltration of chemotherapeutic drugs, and improve the chemotherapeutic sensitivity. ${ }^{13,14}$ Moreover, surgical removal of necrotic tissue and tumor tissue with poor blood supply can eliminate those tissues that are not sensitive to chemotherapy.

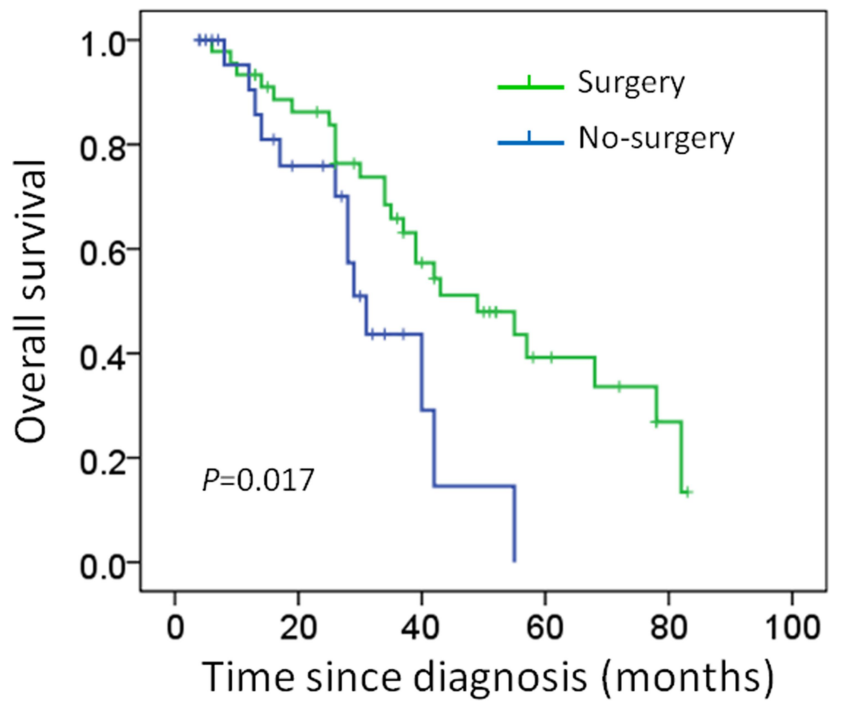

Figure 2 Kaplan-Meier curves estimate overall survival in de novo stage IV breast cancer with bone metastasis only (Median survival was 40 months in the surgery group vs 23 months in the no surgery group; Log rank test: $P=0.017$ ). 


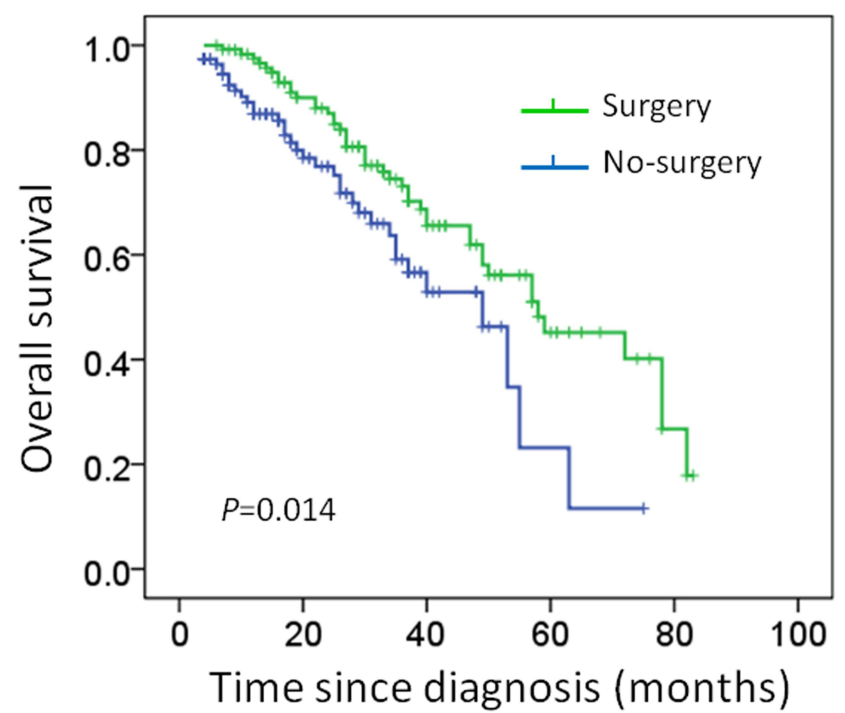

Figure 3 Kaplan-Meier curves estimate overall survival in de novo stage IV breast cancer with metastases sites $\leq 3$ (Median survival was 35 months in the surgery group vs 22 months in the no surgery group; Log rank test: $P=0.014$ ).

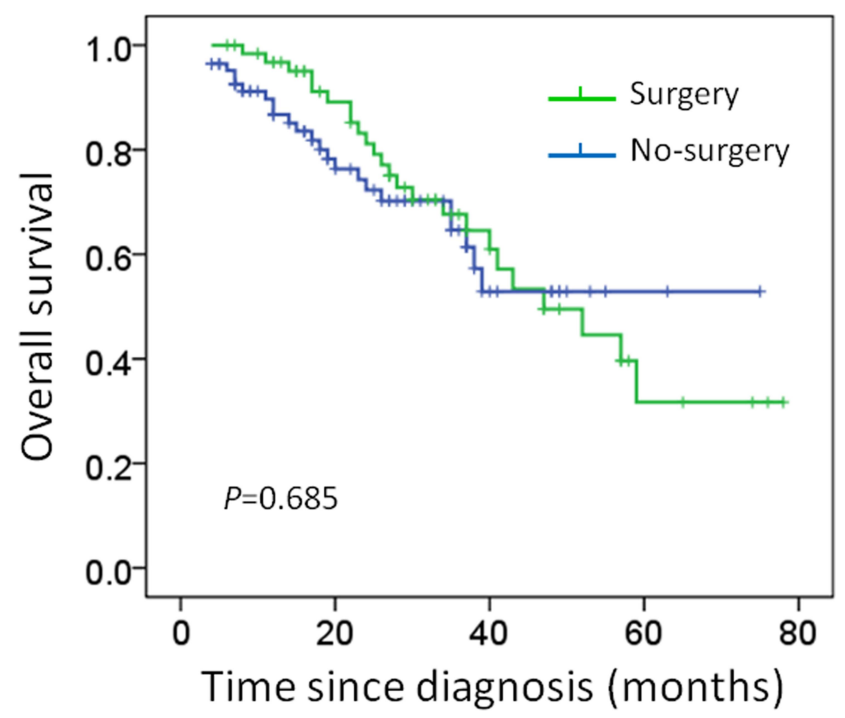

Figure 4 Kaplan-Meier curves estimate overall survival in de novo stage IV breast cancer with visceral metastases (Median survival was 26 months in the surgery group vs 23 months in the no surgery group; Log rank test: $P=0.685$ ).

In addition, removal of tumor stem cells from primary foci reduces the production of drug-resistant cell lines. The "self-planting" theory holds that the primary tumor is not only the source of the metastasis but also the tumor cells from the primary tumor can return to the primary tumor and continue to grow through the circulatory system, these results suggest that circulating tumor cells are helpful for tumor growth, and resection of primary tumor can inhibit tumor growth. ${ }^{15}$ Omard et al demonstrated that primary tumors can affect the progression of metastatic tumors by the release of immunosuppressive cells (MDSCs). Surgical removal of the primary tumor can increase the expression of CD4 +/CD8 + T lymph node cells, to promote the recovery of immune response, extend the survival of patients. $^{16}$

The earliest clinical study was a retrospective study from The National Cancer Data Base (NCDB). It included a total of 16,023 newly diagnosed stage IV breast cancer patients from 1990 to 1993 . Of these patients, $57.2 \%$ underwent primary resection (including breast-conserving surgery and mastectomy). The risk of death was reduced by $39 \%$ in patients who had negative results for surgical margin cancer. The 3 -year survival rate was $35 \%$, compared with $26 \%$ in the positive group and $17.3 \%$ in the non-operative group. ${ }^{17}$ Gnerlich et al collected data from the SEER (Surveillance, Epidemiology, and End Results) database from 1988 to 2003 and enrolled 9734 patients with newly diagnosed stage IV breast cancer whose median survival was longer in the surgery group than in the non-surgery group (36 months vs 21 months, $P<0.001$ ). The mean time of death during follow-up was 18 months and 7 months, respectively $(P<0.001) .{ }^{18}$ In another study from the Baylus School of Medicine, ${ }^{19}$ the median survival was 27.1 months in the surgical group and 16.8 months in the nonsurgical group of 807 newly diagnosed stage IV breast cancer patients, the survival time of the operation group was significantly prolonged $(P<0.0001)$. Multivariate analysis showed that primary tumor resection was one of the independent prognostic factors in newly diagnosed stage IV breast cancer $(P=0.006)$. However, most of the patients in the non-operative group in this study were stage IV breast cancer patients with ER, PR negative and multiple organ metastases or multiple metastases and large tumors. The lack of comparability of these studies may lead to inaccuracy of their results.

At present, the international prospective control study on whether or not to operate on the newly diagnosed stage IV breast cancer gradually attracts more and more attention. In a Turkish randomized prospective trial (MF07-01), patients were randomized into surgery and no surgery groups. The 3 -year OS of the two groups was $60 \%$ vs $51 \%$, and there was no significant difference. However, the OS difference was seen on prolonged follow-up, showed a 5-year OS benefit of surgery in younger patients (age < 55 years), "bone only" metastasis group, and in ER-positive patients. ${ }^{3}$ On the contrary, A randomized prospective trial in India (NCT00193778) and a registry-based prospective study in 
the United States (TBCRC013) have shown no survival benefit in patients treated with primary surgery. ${ }^{4,12}$ The Indian study enrolled 350 newly diagnosed breast cancer patients after six cycles of effective anthracycline chemotherapy, the patients were randomly divided into local treatment group (surgery and adjuvant radiotherapy if necessary) and non-local treatment group. Although there was a significant benefit in terms of local recurrence-free survival with local treatment, there was no benefit for OS. However, taxanes were not used in palliative care in this study cohort, and only $2 \%$ of HER2-positive patients received targeted therapy with Herceptin. The TBCRC013 study included 112 newly diagnosed stage IV breast cancer patients undergoing first-line systemic therapy, after first-line chemotherapy, local surgery was performed in $41 \%$ of the patients in the effective group, and there was no significant difference in 3-year OS between surgery group and non-surgery group. Therefore, the investigators believed that the efficacy of chemotherapy is an important prognostic factor in newly diagnosed stage IV breast cancer patients, and that local surgery does not further improve survival benefits when systemic therapy is effective. These varied results may be attributed to the heterogeneity of stage IV breast cancer, so there is a need to identify the exact cohort of patients who can be expected to benefit from local surgery.

The purpose of this retrospective study was to explore whether primary tumor resection affects survival in patients with de novo stage IV breast cancer and to identify the population that is expected to benefit from the surgery. In our study, $51.6 \%$ of patients underwent surgery for primary tumors, while only $48.4 \%$ did not receive surgery. The results showed that surgery was associated with better survival outcomes even after controlling for important variables such as age, ER and PR expression, number of metastatic sites, and presence of bone metastases. In previous studies, it was reported that negative margins, bone-only metastasis and systemic therapy were the favorable independent factors for survival, while positive margins, overexpression of HER2/neu and visceral metastasis were the adverse prognostic factors. ${ }^{7,19,20}$ In this study, patients with ER and PR positive tumors had better prognosis. ER and PR status were independent prognostic factors, suggesting that tumor biology plays an important role in overall survival. The correlation between biological characteristics of primary tumors (such as mitotic index, differentiation, tumor grade) and survival rates in cancer patients has been confirmed by many related studies. ${ }^{21,22}$ It is worth noting that in our study, only $53.7 \%$ hormone receptor-positive patients received endocrine therapy, and 39.8\% HER2-positive patients received HER2-targeted therapy. The main reason is that some patients with visceral metastasis or rapid progress, their systemic treatment was chemotherapy, rather than endocrine treatment. In addition, a large proportion of patients did not receive HER2-targeted therapy for economic reasons. It is clear that failure to receive targeted therapy may affect survival. But, there were no significant differences between the surgical and non-surgical groups with regard to receipt of anti-HER2 therapy, so it does not affect our prognostic analysis.

Bone is the most common site of metastasis in breast cancer patients. ${ }^{23}$ Patients with bone metastases are more sensitive to systemic therapy and have a better prognosis than patients with other metastases. ${ }^{24}$ Thus, patients with bone metastases who respond to systemic therapy may derive additional benefits from local surgery. Previous studies have found that local surgery reduces mortality in breast cancer patients with bone metastases. ${ }^{25,26}$ Our study also showed that patients with only bone metastases benefit from surgery. We also observed a less-reported survival advantage in patients with non-visceral metastases or $\leq 3$ metastasis sites after local surgery.

The effectiveness of local surgery in de novo stage IV breast cancer remains uncertain. Our results, which showed that resection of primary tumor could significantly improve overall survival in de novo stage IV breast cancer, are consistent with the findings of several previous studies, including one RCT. ${ }^{3}$ However, it is important to acknowledge that our conclusions are different from two RCTs. ${ }^{4,12}$ There are several possible reasons. First, because of our retrospective nature, selection bias still played a confusing role in the survival-benefit ratio, although we did a Cox regression analysis. Second, due to clinical and biological heterogeneity in breast cancer, outcomes in stage IV breast cancer vary with the site of metastasis, molecular subtype, systemic therapy and its response and so on. In Phase III trials at Tata Memorial Hospital in India, there was an age limit of 65 years, and most of the patients (96\%) had unresectable, symptomatic tumors. Taxane and HER2-targeted therapy were administered in only a small number of patients ( $4 \%$ and $2 \%$, respectively, in local treatment group and non-local treatment group). The median follow-up duration was relatively short (23 months). In comparison, our study included 31 patients over 65 years of age, $48.6 \%$ (vs 30\%) had HER2-positive disease and 39.8\% of them received HER2 targeted therapy, and 31\% had resectable tumors. Given the heterogeneity of the disease and varied 
response rates to locoregional treatment, there is a need to identify the exact cohort of patients who can be expected to benefit from local surgery in future.

The current study has some limitations because of its retrospective nature. First, this is a single-center study with a small number of patients, representing only patients from the Southwest China. Second, the surgery group included patients with more favorable prognostic factors, leading to selection bias. It is likely that physicians recommended local surgery more readily for patients who did not have a heavy tumor burden at the time of the treatment decision. Patients who had a good response to systemic therapy may be identified as having a more controllable disease and require a subsequent surgery by chance. Therefore, our findings need to be validated in a larger multicenter prospective study.

\section{Conclusions}

Our study shows that primary tumor resection in de novo stage IV breast cancer patients has a positive effect on survival, and surgery is independently associated with improved survival. Especially for patients with bone metastasis only and $\leq 3$ metastatic sites, the combination of local surgery and systemic therapy is reasonable.

\section{Author Contributions}

All authors made substantial contributions to conception and design, acquisition of data, or analysis and interpretation of data; took part in drafting the article or revising it critically for important intellectual content; agreed to submit to the current journal; gave final approval of the version to be published; and agree to be accountable for all aspects of the work.

\section{Disclosure}

The authors report no conflicts of interest in this work.

\section{References}

1. DeSantis CE, Ma J, Gaudet MM, et al. Breast cancer statistics, 2019. CA Cancer J Clin. 2019;69(6):438-451. doi:10.3322/caac.21583

2. Tyagi NK, Dhesy-Thind S. Clinical practice guidelines in breast cancer. Curr Oncol. 2018;25(Suppl 1):S151-S160. doi:10.3747/ co. 25.3729

3. Soran A, Ozmen V, Ozbas S, et al. Randomized trial comparing resection of primary tumor with no surgery in stage iv breast cancer at presentation: protocol MF07-01. Ann Surg Oncol. 2018;25 (11):3141-3149. doi:10.1245/s10434-018-6494-6

4. King TA, Lyman JP, Gonen M. Prognostic impact of 21-gene recurrence score in patients with stage iv breast cancer: TBCRC 013. J Clin Oncol. 2016;34(20):2359-2365. doi:10.1200/JCO.2015.63.1960

5. Santa-Maria CA, Gradishar WJ. Changing treatment paradigms in metastatic breast cancer: lessons learned. JAMA Oncol. 2015;1 (4):528-534. doi:10.1001/jamaoncol.2015.1198
6. Bleicher RJ, Ruth K, Sigurdson ER, et al. Time to surgery and breast cancer survival in the United States. JAMA Oncol. 2016;2(3):330339. doi:10.1001/jamaoncol.2015.4508

7. Xiong Z, Deng G, Wang J, et al. Could local surgery improve survival in de novo stage IV breast cancer? BMC Cancer. 2018;18 (1):885. doi:10.1186/s12885-018-4767-x

8. Wang W, Liu J, Wang J, Gao J, Wang X, Wang X. Impact of locoregional treatment on prognosis of de novo stage iv breast cancer: a retrospective long-term study of chinese population. Gynecol Obstet Invest. 2019;84(3):248-258. doi:10.1159/000488643

9. Desille-Gbaguidi H, Avigdor S, Body G, Ouldamer L. Survival impact of primary site surgery on metastatic breast cancer patients at diagnosis. J Gynecol Obstet Hum Reprod. 2019;48(3):171-177. doi:10.1016/j.jogoh.2018.10.014

10. Leung AM, Vu HN, Nguyen KA, Thacker LR, Bear HD. Effects of surgical excision on survival of patients with stage IV breast cancer. $J$ Surg Res. 2010;161(1):83-88. doi:10.1016/j.jss.2008.12.030

11. Bafford AC, Burstein HJ, Barkley CR, et al. Breast surgery in stage IV breast cancer: impact of staging and patient selection on overall survival. Breast Cancer Res Treat. 2009;115(1):7-12. doi:10.1007/ s10549-008-0101-7

12. Badwe R, Hawaldar R, Nair N, et al. Locoregional treatment versus no treatment of the primary tumour in metastatic breast cancer: an open-label randomised controlled trial. Lancet Oncol. 2015;16 (13):1380-1388. doi:10.1016/S1470-2045(15)00135-7

13. Ren Z, Li Y, Hameed O, Siegal GP, Wei S. Prognostic factors in patients with metastatic breast cancer at the time of diagnosis. Pathol Res Pract. 2014;210(5):301-306. doi:10.1016/j.prp.2014.01.008

14. Ranji P, Salmani Kesejini T, Saeedikhoo S, Alizadeh AM. Targeting cancer stem cell-specific markers and/or associated signaling pathways for overcoming cancer drug resistance. Tumour Biol. 2016;37 (10):13059-13075. doi:10.1007/s13277-016-5294-5

15. Kim MY, Oskarsson T, Acharyya S, et al. Tumor self-seeding by circulating cancer cells. Cell. 2009;139(7):1315-1326. doi:10.1016/j. cell.2009.11.025

16. Rashid OM, Nagahashi M, Ramachandran S, et al. Resection of the primary tumor improves survival in metastatic breast cancer by reducing overall tumor burden. Surgery. 2013;153(6):771-778. doi:10.1016/j.surg.2013.02.002

17. Khan SA, Stewart AK, Morrow M. Does aggressive local therapy improve survival in metastatic breast cancer? Surgery. 2002;132 (4):620-626. doi:10.1067/msy.2002.127544

18. Gnerlich J, Jeffe DB, Deshpande AD, Beers C, Zander C, Margenthaler JA. Surgical removal of the primary tumor increases overall survival in patients with metastatic breast cancer: analysis of the 1988-2003 SEER data. Ann Surg Oncol. 2007;14(8):2187-2194. doi:10.1245/s10434-007-9438-0

19. Blanchard DK, Shetty PB, Hilsenbeck SG, Elledge RM. Association of surgery with improved survival in stage IV breast cancer patients. Ann Surg. 2008;247(5):732-738. doi:10.1097/SLA.0b013e3181656d32

20. Choi SH, Kim JW, Choi J, et al. Locoregional treatment of the primary tumor in patients with de novo stage iv breast cancer: a radiation oncologist's perspective. Clin Breast Cancer. 2018;18(2): e167-e178. doi:10.1016/j.clbc.2017.06.002

21. Pece S, Disalvatore D, Tosoni D, et al. Identification and clinical validation of a multigene assay that interrogates the biology of cancer stem cells and predicts metastasis in breast cancer: a retrospective consecutive study. EBioMedicine. 2019;42:352-362. doi:10.1016/j. ebiom.2019.02.036

22. Daly B, Olopade OI. A perfect storm: how tumor biology, genomics, and health care delivery patterns collide to create a racial survival disparity in breast cancer and proposed interventions for change. $C A$ Cancer J Clin. 2015;65(3):221-238. doi:10.3322/caac.21271

23. Xiong Z, Deng G, Huang X, et al. Bone metastasis pattern in initial metastatic breast cancer: a population-based study. Cancer Manag Res. 2018;10:287-295. doi:10.2147/CMAR.S155524 
24. Briasoulis E, Karavasilis V, Kostadima L, Ignatiadis M, Fountzilas G, Pavlidis N. Metastatic breast carcinoma confined to bone: portrait of a clinical entity. Cancer. 2004;101(7):1524-1528. doi:10.1002/ cncr. 20545

25. Neuman HB, Morrogh M, Gonen M, Van Zee KJ, Morrow M, King TA. Stage IV breast cancer in the era of targeted therapy: does surgery of the primary tumor matter? Cancer. 2010;116(5):12261233. doi: $10.1002 / \mathrm{cncr} .24873$
26. Cady B, Nathan NR, Michaelson JS, Golshan M, Smith BL. Matched pair analyses of stage IV breast cancer with or without resection of primary breast site. Ann Surg Oncol. 2008;15(12):3384-3395. doi:10.1245/s10434-008-0085-x

\section{Publish your work in this journal}

Cancer Management and Research is an international, peer-reviewed open access journal focusing on cancer research and the optimal use of preventative and integrated treatment interventions to achieve improved outcomes, enhanced survival and quality of life for the cancer patient.
The manuscript management system is completely online and includes a very quick and fair peer-review system, which is all easy to use. Visit http://www.dovepress.com/testimonials.php to read real quotes from published authors. 